Article

\title{
Interaction of Preventive, Cultural, and Direct Methods for Integrated Weed Management in Winter Wheat
}

\author{
Alexander Menegat 1,*(D) and Anders T. S. Nilsson ${ }^{2}$ \\ 1 Department of Crop Production Ecology, Swedish University of Agricultural Sciences, \\ 75007 Uppsala, Sweden \\ 2 Department of Biosystems and Technology, Swedish University of Agricultural Sciences, \\ 23053 Alnarp, Sweden; anders.ts.nilsson@slu.se \\ * Correspondence: alexander.menegat@slu.se; Tel.: +46-18-671-000
}

Received: 10 September 2019; Accepted: 17 September 2019; Published: 19 September 2019

\begin{abstract}
Crop rotations dominated by winter annual crops and relying on the use of herbicides to control weeds have resulted in weed communities dominated by a few highly specialized species such as Alopecurus myosuroides. Integrated weed management (IWM) represents a sensible strategy to target such difficult weeds, through a combination of preventive, cultural, and direct means. In six field trials over three years, we tested the effect of stale seedbed preparation, winter wheat seed rate, and chemical weed control strategy on Alopecurus myosuroides control efficacy and variability in efficacy. The field experiments were carried out under reduced tillage practice and without pre-sowing use of glyphosate. Stale seedbed preparation alone reduced A. myosuroides infestation level by $25 \%$ on average. No clear effect was found of increasing winter wheat seed rate from 300 to 400 seeds $\mathrm{m}^{-2}$. A combination of stale seedbed preparation and herbicide treatment in autumn and spring was found to be synergistic, improving weed control efficacy significantly and moreover reducing the variability in control efficacy and hence the risk for weed control failure.
\end{abstract}

Keywords: IWM, black-grass; sowing time; stale seedbed, seed rate; weed control; Alopecurus myosuroides

\section{Introduction}

As part of the so-called 'green revolution', the development and use of herbicides helped lay the foundation for reducing yield losses and improving yield stability in global agriculture [1]. Herbicides have also enabled the uptake of reduced tillage and no-tillage practices, a major step towards soil conservation, especially in agricultural regions with marginal pedoclimatic conditions $[2,3]$. Reduced/no-tillage practices have also enabled the economic optimization of farms, through reducing labor requirements and associated costs, and through reducing overall energy consumption [4]. In temperate regions of central Europe, these developments have enabled the implementation of intensive production systems for cultivation of winter wheat, barley, and winter oilseed rape. These systems, hereafter termed 'conventional' production systems, are typically characterized by reduced tillage with alternating inversion tillage, combined with frequent use of mineral fertilizers and pesticides. Sowing dates, seed rates, and cultivar choice are optimized to achieve maximum yield. Weed control is achieved solely by use of herbicides. This overreliance on herbicides in conventional farming has caused novel and complex problems, including the rapid evolution and spread of herbicide-resistant weeds [5], pesticide contamination of the environment and food chain [6,7], health risks to pesticide users and end consumers [8], and a tremendous loss of biodiversity in agro-ecosystems [9]. Weed'communities in conventional systems have become highly 
specialized, and are typically dominated by a few highly competitive and often herbicide-resistant weed species. Alopecurus myosuroides Huds. (black-grass) is an example of a weed species that is thriving in conventional cropping systems in central and northern Europe, which are based on winter annual crops. A closer look at the life cycle of $A$. myosuroides reveals its perfect adaptation to these cropping systems. Peak germination and emergence occur in early autumn, coinciding with the sowing time and early development stages of winter cereals. Maximum burial depth for successful germination and emergence of $A$. myosuroides is believed to be $5 \mathrm{~cm}$, and thus reduced tillage systems provide optimal growing conditions [10,11]. A low germination base temperature of $0{ }^{\circ} \mathrm{C}[12]$ allows a wide emergence period until early winter, with a smaller proportion of plants emerging in early spring. After overwintering in a two-leaf to five-tiller growth stage, $A$. myosuroides vigorously resumes growth in spring and completes its life cycle well before crop harvest [13]. Beyond its perfectly adapted life cycle, the abundance of herbicide-resistant $A$. myosuroides populations has constantly increased during recent decades, with great variability in resistance mechanisms and resistance patterns [14].

For A. myosuroides control, up to four herbicide treatments are required in conventional farming systems, comprising pre-sowing glyphosate use, pre-emergence herbicide use shortly after crop sowing, and post-emergence herbicide treatments in autumn and spring. The reasons for this high level of chemical weed control lie mostly in cultural practice: Early sowing prevents A. myosuroides from emerging before the crop, and hence from being removed mechanically through seedbed preparation and the sowing process. The use of seed rates and cultivars is optimized for yield and not competition, resulting in crop stands with low competitiveness against weeds during autumn and spring and, in the worst case, throughout the entire cropping season [15].

Potential for addressing the problems with persistent weeds can be provided through the progress achieved in recent years toward development of integrated weed management systems (IWM). The concept of IWM involves systematic and combined use of preventive, cultural, and direct weed control techniques [16]. Preventive weed control measures are applied between the crop growing seasons, aiming to reduce weed emergence during the cropping season. Cultural measures are applied during the cropping season, aiming to increase crop competitiveness. Direct control measures are applied during the cropping season, aiming to control weed plants that have escaped the preventive and cultural control measures [17]. Recent studies have demonstrated that the overall sustainability, comprising economic, environmental and social sustainability, of IWM systems surpasses that of conventional cropping systems. In many cases, the environmental disadvantages of pesticide use outweigh any potential socio-economic benefits [18], which may be further undermined by health risks to farm workers and end consumers [8]. A shift towards IWM and away from conventional cropping systems has therefore become a social, economic, and ecological imperative.

In this study, we performed a series of field experiments at six sites in south-western Sweden with the aim of examining the potential of IWM for A. myosuroides control. The effects of stale seedbed preparation (preventive control), winter wheat planting density (cultural control), and herbicide application timing (direct control) on A. myosuroides density and seed production were examined in the experiments. The experimental design permitted analysis of each experimental factor separately, as well as their cumulative effects. Although numerous studies have evaluated the effect of individual IWM components on A. myosuroides [19,20], and one study has modelled their cumulative effects [21], knowledge is lacking about whether the cumulative effects are additive, synergistic, or antagonistic. Averting the risk of weed control failure, which is associated with high variability in efficacy, is equally important to weed control efficacy. Non-chemical, preventive, and cultural weed control options are reported to have greater variability in efficacy than herbicides [20]. In this study, we attempted to evaluate the variability in efficacy of IWM strategies as a whole, and that of their individual components. 


\section{Materials and Methods}

\subsection{Experimental Design}

Conventional experimental designs typically repeat experiments over a limited number of sites and/or over a limited number of years. The range of pedoclimatic variation that can be covered by this approach is naturally rather limited. To test the variability in efficacy of individual and combined weed management measures, repeating the experiment under as many different pedoclimatic conditions as possible is desirable. To satisfy this requirement, we performed replicate experiments over time and at different experimental sites.

Six field experiments were established in south-western Sweden and assessed between 2013 and 2016. Selection of experimental sites was made with respect to the above-mentioned aim of covering as much pedoclimatic variation as possible within the three experimental years. Accordingly, two experiments at two different sites were conducted each year. Through changing the experimental sites each year, data for six unique site-year combinations were obtained.

The climate at the experimental sites is characterized as warm and temperate oceanic (Köppen-Geiger climate classification: $\mathrm{Cfb}$ ), with mean annual temperature ranging between 7 and $10^{\circ} \mathrm{C}$ and considerable variation in annual rainfall, ranging between 650 and $1100 \mathrm{~mm}$. Soil texture at the sites is clay loam (ClLo), sandy clay loam (SaClLo), or sandy loam (SaLo). The previous crop at all experimental sites was winter oilseed rape (Brassica napus L.) or oats (Avena sativa L.). During the years before the experiments were conducted, soil and crop management was similar at all sites, comprising mouldboard ploughing before oilseed rape and reduced tillage (shallow stubble cultivation and seedbed preparation) before winter cereals. Weed management was achieved solely by the use of herbicides. Alopecurus myosuroides was the dominant weed species at all experimental sites, while other weed species were present only in negligible densities. All experiments were set up under reduced tillage practice and without pre-seeding glyphosate use.

Apart from the differing site-year combinations, the experiments comprised the following three experimental factors (factor levels are given in brackets):

(i) Sowing strategy (2): An early and a late sowing date for winter wheat (Triticum aestivum L.), differing by 21 days on average, were tested at each site. Late sowing was aimed for the end of September at the latest, because a further delay in sowing would pose an unacceptable risk to operations due to wet weather conditions. The exact sowing date was year- and site-specific, with an average early date of around 8 September and an average late date of around 29 September. Seedbed preparation was performed in all experimental plots within seven days before the early sowing, and once again shortly before sowing in plots assigned for late sowing. This approach resulted in a stale seedbed for the late sowing date.

(ii) Seed rate (2): Winter wheat was sown at two seed rates: A typical farm seed rate of 300 seeds $\mathrm{m}^{-2}$ and an increased seed rate of 400 seeds $\mathrm{m}^{-2}$.

(iii) Herbicide strategy (4): Beside an untreated control, three herbicide strategies were tested: A pre-emergence autumn treatment with 3.0 L prosulfocarb $\left(800 \mathrm{~g} \mathrm{~L}^{-1}\right)$, applied within seven days after winter wheat sowing; a post-emergence spring treatment with $0.9 \mathrm{~L}$ mesosulfuron-methyl $\left(10 \mathrm{~g} \mathrm{~L}^{-1}\right)+$ iodosulfuron-methyl-sodium $\left(2 \mathrm{~g} \mathrm{~L}^{-1}\right)+$ non-ionic surfactant, applied at the beginning of the growing period (from mid- to late April); a combination of these autumn and spring treatments.

The resulting 16 treatment combinations of sowing date (2), seed rate (2), and herbicide strategy (4) were arranged in a randomized strip-split-plot design with four replicates per treatment combination (64 plots). Within each block $(16 \mathrm{~m} \times 24 \mathrm{~m})$, sowing dates were randomly arranged as main plots $(8 \mathrm{~m} \times 24 \mathrm{~m})$. Seed rates were randomly arranged as sub-plots within the main plots. Herbicide strategies were arranged as non-randomized strips across the four blocks. The resulting final plot size was $4 \mathrm{~m} \times 6 \mathrm{~m}$. 


\subsection{Data Collection}

One week before harvesting of winter wheat, plant and ear counting was carried out on A. myosuroides at four randomly chosen positions per plot within a $50 \mathrm{~cm} \times 50 \mathrm{~cm}$ frame. The average number of ears per plant was calculated by dividing the number of ears per frame by the number of plants per frame. Winter wheat yield was determined by using a plot combine harvester to harvest a strip $1.5 \mathrm{~m}$ wide and $24 \mathrm{~m}$ long in the centre of each plot. Plots had to be harvested across the four herbicide treatment strips, so the yield data presented here represent the effect of winter wheat sowing strategy and seed rate averaged over the four herbicide strategies tested.

\subsection{Statistical Analysis}

Generalized linear mixed effect models (GLMMs) with Poisson distribution and logarithmic link function were used for exploring the relationships between the observed A. myosuroides infestation levels. The three experimental factors were considered as fixed effects, i.e., (i) crop sowing strategy, (ii) crop seed rate, and (iii) herbicide treatment strategy. The experimental design had a hierarchical structure, with four strata used as random effects: (1) the block, representing variability due to the four blocks in each experiment; (2) the main plot, representing variability due to the two sowing times randomized within each of the four blocks; (3) the herbicide treatment strip, representing variability due to the four herbicide treatment strips across the four blocks; and (4) the environment, representing variability in pedoclimatic conditions caused by differing experimental sites and experimental years.

All models were checked for homogenous variance in the residuals and for collinearity among the explanatory variables, using variance inflation factor (VIF). Analysis of deviance tables were computed using the type II Wald F-test with Kenward-Roger approximation for degrees of freedom. To represent the proportion of variance explained by the fixed effects of the models, the marginal coefficient of determination $R_{G L M M(m)}^{2}$ for GLMMs was calculated [22]. The intra-class correlation coefficient (ICC), representing the proportion of variance explained by a random factor in multilevel/ hierarchical data [22,23], was also calculated. Akaike information criterion (AIC) was used for model comparison and model selection purposes [24]. Full and reduced models were compared by means of Akaike weights, representing the relative weight of evidence for the model [25]. All analyses were performed with $R[26]$.

\subsection{Assessment and Interpretation of Variability in Weed Control Efficacy and Interaction with Agronomic Practice}

The variability in weed control efficacy was assessed based on the average A. myosuroides density estimates and the $95 \%$ confidence limits derived from the GLMM described above. The observed percentage reduction in A. myosuroides density (Efficacy) was calculated based on the estimated average $A$. myosuroides density in each treatment combination $\left(D_{T}\right)$ with reference to the control treatment $\left(D_{U}\right)$. The control treatment was defined as the combination of early sowing, no herbicide treatment, and a winter wheat seed rate of 300 seeds $\mathrm{m}^{-2}$.

$$
\text { Observed efficacy }(\%)=100-\frac{D_{T} * 100}{D_{U}}
$$

The differences relative to the control treatment of the $95 \%$ confidence limits were calculated in the same way.

The nature of the interaction between the levels of experimental factors tested was assessed by calculating the expected efficacy of the treatment combinations according to $[27,28]$ :

$$
\text { Expected efficacy }(\%)=100-\frac{X * Y * Z}{10,000}
$$


where $X$ is the $A$. myosuroides survival rate under individually altered sowing time, $Y$ is the $A$. myosuroides survival rate under individually altered winter wheat seed rate, and $Z$ is the $A$. myosuroides survival rate under individually altered herbicide treatment strategy.

The calculated expected efficacy was compared with the observed weed control efficacy of the respective treatment combination. Expected efficacy values that are greater than the actual efficacy indicate antagonism between the factor combinations tested, while expected efficacy values lower than the actual efficacy can be interpreted as indicating synergism between the factor combinations tested.

\section{Results}

\subsection{Random Effects Analysis and Model Summary Statistics on A. myosuroides Density}

Pedoclimatic differences between experimental sites (random effect environment) accounted for a greater proportion of the variation in A. myosuroides density than main plot or herbicide strip. Variance due to the random effect block was close to zero. This indicates that the variance within the experimental sites was almost fully explained by the lower hierarchical grouping factors main plot and herbicide strip, so further consideration of the higher hierarchical grouping factor block was not required. According to the ICC values, pedoclimatic differences between experimental sites explained $37 \%$ of the observed variance, herbicide strips $25 \%$, and main plot $34 \%$. The proportion of variance explained by the model fixed effects was $28 \%$ (Marginal $\mathrm{R}^{2}=0.278$ ), while the proportion of variance explained by fixed and random effects together was $97 \%\left(\right.$ Conditional $\left.R^{2}=0.966\right)$ (Table 1A).

Table 1. Summary of generalized linear mixed model results with: (A) Alopecurus myosuroides density as dependent variable, (B) A. myosuroides ears plant ${ }^{-1}$ as dependent variable, and (C) winter wheat yield as dependent variable.

\begin{tabular}{|c|c|c|c|c|c|c|c|}
\hline & Analysis & Random Effect & Variance & $\begin{array}{l}\text { Standard } \\
\text { Deviation }\end{array}$ & $\begin{array}{l}\text { Intraclass } \\
\text { Correlation } \\
\text { Coefficient }\end{array}$ & Marginal $\mathbf{R}^{2}$ & Conditional $\mathbf{R}^{2}$ \\
\hline \multirow{3}{*}{ (A) } & \multirow{3}{*}{$\begin{array}{l}\text { A. myosuroides } \\
\text { plants } \mathrm{m}^{-2}\end{array}$} & Main plot & 0.675 & 0.822 & 0.344 & \multirow{3}{*}{0.278} & \multirow{3}{*}{0.966} \\
\hline & & Herbicide strip & 0.497 & 0.705 & 0.246 & & \\
\hline & & Environment & 0.751 & 0.867 & 0.372 & & \\
\hline \multirow{4}{*}{ (B) } & \multirow{4}{*}{$\begin{array}{l}\text { A. myosuroides } \\
\text { ears plant }^{-1}\end{array}$} & Main plot & 0.067 & 0.259 & 0.063 & \multirow{4}{*}{0.361} & \multirow{4}{*}{0.83} \\
\hline & & Herbicide strip & 0.317 & 0.563 & 0.299 & & \\
\hline & & Block & 0.080 & 0.283 & 0.076 & & \\
\hline & & Environment & 0.315 & 0.561 & 0.297 & & \\
\hline \multirow{3}{*}{ (C) } & \multirow{3}{*}{$\begin{array}{c}\text { Winter } \\
\text { wheat yield }\end{array}$} & Main plot & 0.004 & 0.063 & 0.112 & \multirow{3}{*}{0.051} & \multirow{3}{*}{0.996} \\
\hline & & Block & 0.000 & 0.017 & 0.008 & & \\
\hline & & Environment & 0.031 & 0.176 & 0.876 & & \\
\hline
\end{tabular}

\subsection{Fixed Effects Analysis of A. myosuroides Density}

Interactions were found between seed rate and herbicide strategy and between sowing strategy and herbicide strategy. Averaged over the levels of sowing strategy, the high winter wheat seed rate caused a slight reduction in the efficacy of the autumn herbicide treatment, whereas the spring herbicide treatment was not affected by the winter wheat seed rate (Figure 1A). Averaged over the levels of seed rate, delayed sowing of winter wheat combined with stale seedbed preparation improved the efficacy of all three herbicide strategies tested. Without herbicide treatment, a decrease in A. myosuroides density due to stale seedbed preparation was still observed (Figure 1B). 

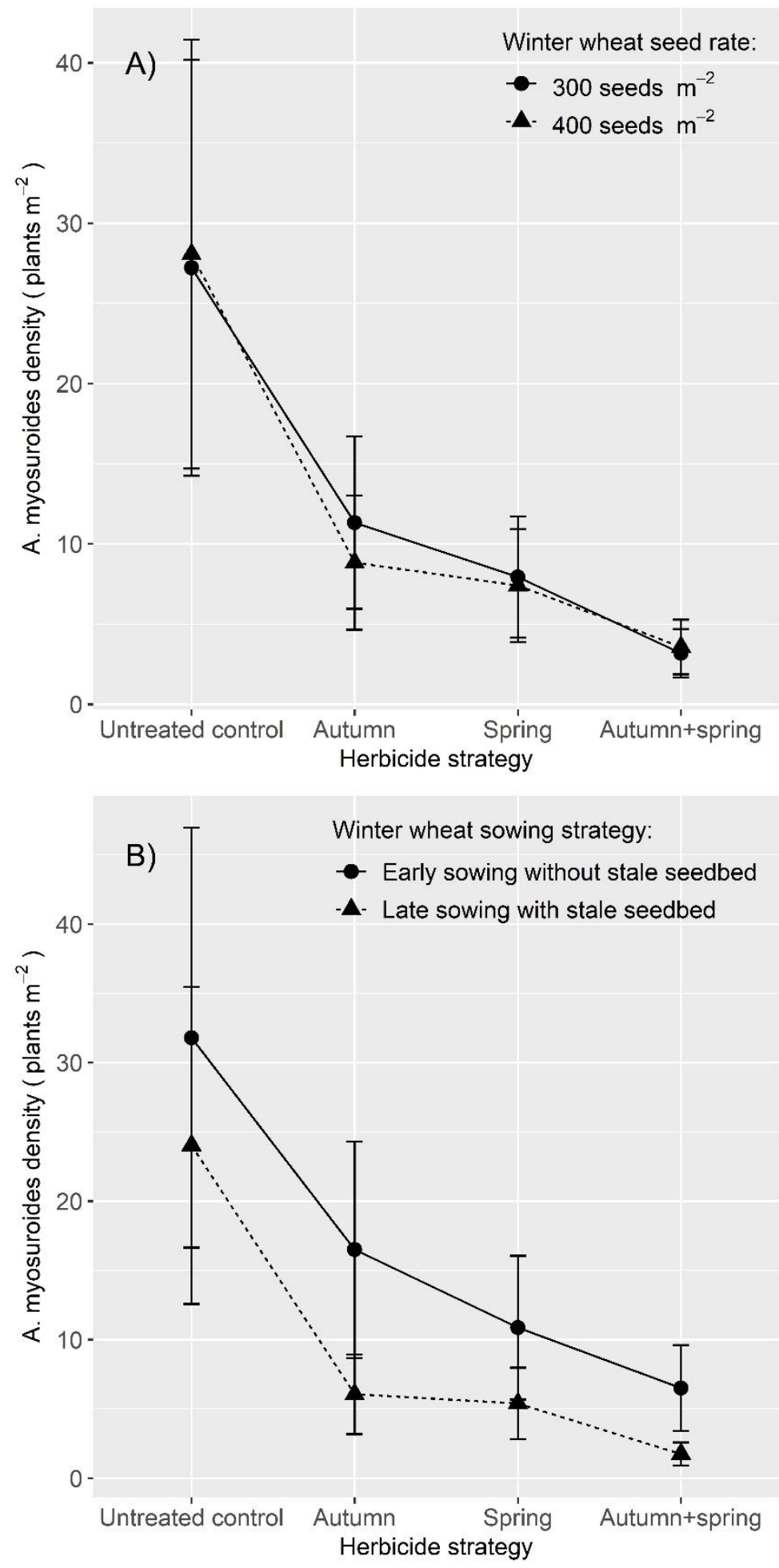

Figure 1. Alopecurus myosuroides plant density as a function of (A) herbicide treatment strategy and winter wheat seed rate and (B) herbicide treatment strategy and winter wheat sowing strategy.

All treatment combinations combining late sowing with stale seedbed preparation and at least one herbicide application succeeded in reducing $A$. myosuroides density by more than $75 \%$. Only the treatment combinations combining late sowing with stale seedbed preparation and herbicide treatments in autumn and spring were able to reduce the A. myosuroides infestation by around $95 \%$ on average. Late sowing with stale seedbed preparation was able to reduce the weed infestation level 
by around $25 \%$ compared with the control treatment (early sowing, no stale seedbed preparation, low seed rate, no herbicide application) (Figure 2).
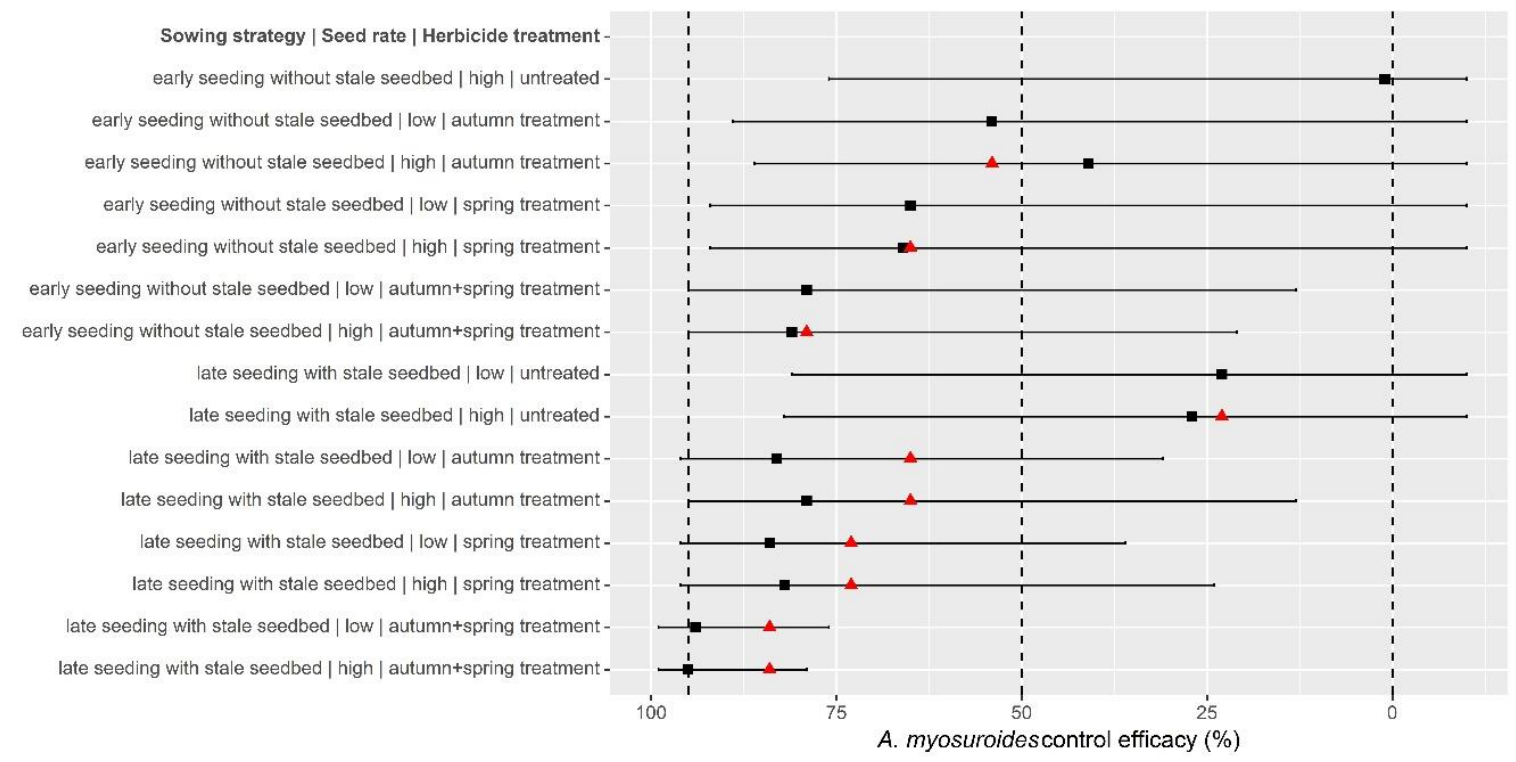

Figure 2. Efficacy of Alopecurus myosuroides control relative to the control treatment, depending on weed management strategy. The control treatment was defined as the combination early sowing, no stale seedbed preparation, no herbicide application, and low winter wheat seed rate. Red triangles represent the calculated expected efficacy for the respective treatment combinations. Black squares represent the observed mean value for the respective treatment combinations. Black bars indicate the $95 \%$ confidence interval. For clarity, the $\mathrm{x}$ axis is arranged in descending order.

Early sowing without stale seedbed preparation in combination with herbicide treatment in autumn and spring was able to reduce the weed infestation level by around $80 \%$ on average.

The range of calculated confidence intervals for each IWM strategy allowed assessment of the risk of weed control failure associated with each of the IWM strategies tested. The fixed effects were tested regarding their influence on the confidence limit range. Sowing strategy and herbicide treatment strategy showed a significant effect on the confidence limit range $(p<0.05)$, whereas the winter wheat seed rate appeared to be non-significant. Averaged over the levels of winter wheat seed rates and herbicide treatment strategies, late crop sowing with stale seedbed preparation reduced the average range of the efficacy confidence limits from $195 \%$ to $112 \%$ compared with early crop sowing without stale seedbed preparation. Averaged over the levels of crop sowing strategy and winter wheat seed rate, all herbicide strategies were able to reduce the confidence limit range compared with the untreated control (331\%). However, the autumn treatment strategy showed a wider confidence limit range $(135 \%)$ than the spring $(99 \%)$ and autumn + spring treatment strategy $(50 \%)$, and therefore a higher risk of weed control failure.

The calculated expected efficacy of late crop sowing with stale seedbed preparation in combination with any herbicide treatment was lower than the actual observed value, irrespective of the winter wheat seed rate. This suggests a synergistic interaction between stale seedbed preparation and herbicide treatment.

\subsection{Random Effects Analysis and Model Summary Statistics on A. myosuroides Ear Production}

Pedoclimatic differences between experimental sites (random effect environment) and herbicide strips accounted for the greatest proportion of variance comparing with main plot and block. According to the ICC values, pedoclimatic differences between experimental sites explained $32 \%$ of the observed variance, herbicide strips $32 \%$, main plot $7 \%$, and blocks $8 \%$. The proportion of variance explained by the model 
fixed effects was $36 \%$ (Marginal $R^{2}=0.361$ ), while the proportion of variance explained by the fixed and random effects together was $83 \%$ (Conditional $R^{2}=0.83$ ) (Table 1B).

\subsection{Fixed Effects Analysis of A. myosuroides Ears Per Plant}

The average number of ears produced per $A$. myosuroides plant was influenced by an interaction between winter wheat sowing strategy and herbicide treatment strategy, whereas no significant effect of seeding rate was found. A general decrease in the number of ears produced per A. myosuroides plant was observed in plots where herbicide treatment took place in spring and in all treatment combinations with stale seedbed preparation. The combined autumn and spring herbicide treatment further reduced the number of ears per plant only marginally compared with a single spring herbicide treatment (Figure 3).

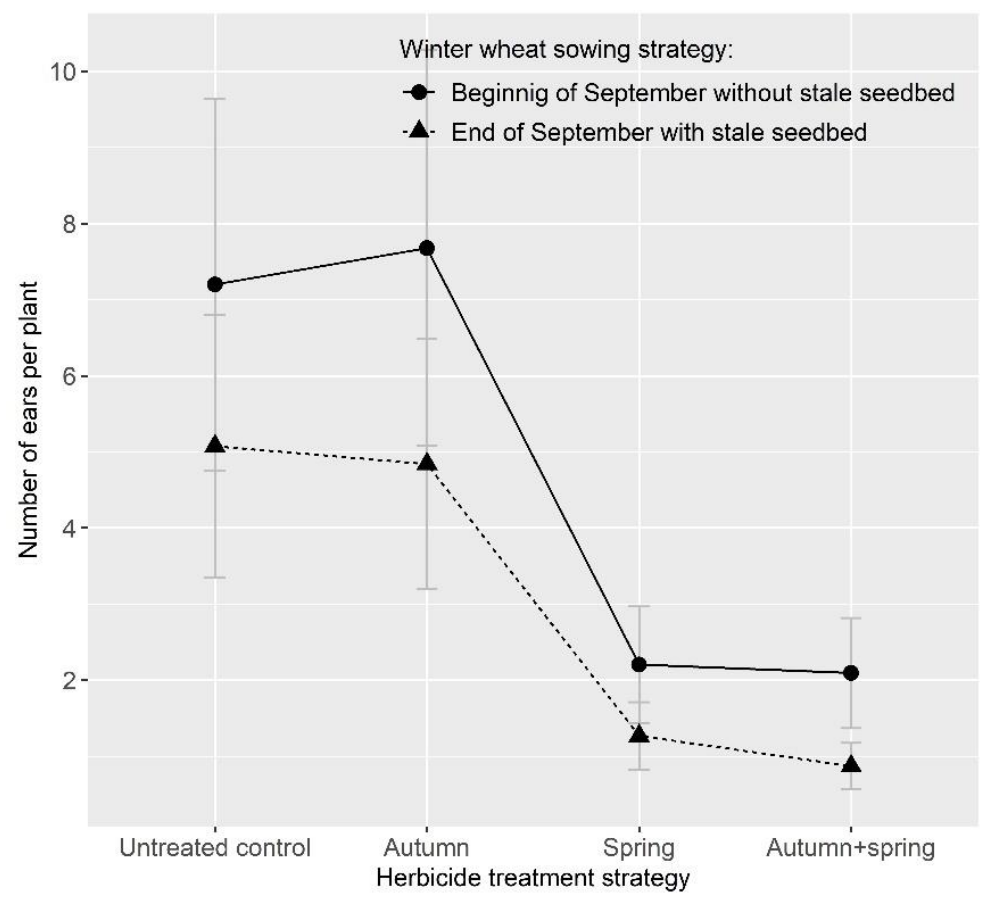

Figure 3. Number of Alopecurus myosuroides ears per plant as a function of herbicide treatment strategy and winter wheat sowing strategy.

\subsection{Effect of Winter Wheat Sowing Strategy and Seed Rate on Winter Wheat Yield}

Plots had to be harvested across the four herbicide treatment strips, so the yield data presented here represent the effect of winter wheat sowing strategy and seed rate averaged over the four herbicide strategies tested.

Based on the ICC values, pedoclimatic differences between experimental sites and years explained $88 \%$ of the observed variance in winter wheat yield. The proportion of variance explained by the model fixed effects was $5 \%$ (Marginal $\mathrm{R}^{2}=0.051$ ), while the proportion of variance explained by the fixed and random effects together was $99 \%$ (Conditional $R^{2}=0.996$ ).

Winter wheat yield was affected by a combination of sowing strategy and seed rate. Under low winter wheat seed rates, early sowing without stale seedbed preparation resulted in an average winter wheat yield of $6.8 \mathrm{tha}^{-1}$, whereas late sowing with stale seedbed preparation resulted in an average winter wheat yield of $7.5 \mathrm{tha}^{-1}$, which is a yield increase of approximately $10 \%$ (Table 2). Higher winter wheat seed rates of 400 seeds $\mathrm{m}^{-2}$ further increased winter wheat yields by approximately $3 \%$ without stale seedbed preparation and approximately $1 \%$ with stale seedbed preparation. 
Table 2. Summary of generalized linear mixed model results with winter wheat yield as dependent variable. $\mathrm{LCL}=$ lower confidence limit, $\mathrm{UCL}=$ upper confidence limit, Sig.= treatments with different lowercase letters are significantly different at $\alpha=0.05$.

\begin{tabular}{|c|c|c|c|c|c|}
\hline Sowing Strategy & $\begin{array}{l}\text { Seed Rate } \\
\text { (seed } \mathrm{m}^{-2} \text { ) }\end{array}$ & $\begin{array}{l}\text { Winter Wheat } \\
\text { Yield }\left(\mathrm{kg} \mathrm{ha}^{-1}\right)\end{array}$ & LCL (kg ha-1) & UCL $\left(\mathrm{kg} \mathrm{ha}^{-1}\right)$ & Sig. \\
\hline End of September with stale seedbed & 400 & 7546 & 6288 & 9057 & $\mathrm{a}$ \\
\hline End of September with stale seedbed & 300 & 7457 & 6213 & 8950 & $\mathrm{~b}$ \\
\hline Beginning of September without stale seedbed & 400 & 6980 & 5816 & 8378 & c \\
\hline Beginning of September without stale seedbed & 300 & 6808 & 5672 & 8171 & $\mathrm{~d}$ \\
\hline
\end{tabular}

\section{Discussion}

In this study, we examined (i) the efficacy of preventive, cultural, and direct weed control measures and the nature of their interaction; (ii) the risk of weed control failure associated with single and combined control measures; and (iii) the proportion of weed density and reproduction variability explained by factors other than those controlled in the experiments. The data presented cover a range of pedoclimatic conditions characteristic for winter annual crop production sites in northern Europe.

Pedoclimatic differences between the environments investigated accounted for the greatest proportion of $A$. myosuroides density and reproduction variability, rather than the different experimental factors. Considering that only $28 \%$ of the observed variation in A. myosuroides density and $36 \%$ of the observed variation in $A$. myosuroides reproduction could be explained by the experimental factors, a large proportion of the probability of weed control failure cannot be controlled by agronomic means (discrepancy between marginal and conditional $\mathrm{R}^{2}$, see Table 1 ). This is partly explained by the biology of $A$. myosuroides: The species is characterized by a low germination base temperature $\left(0{ }^{\circ} \mathrm{C}\right)$ and short primary dormancy $[29,30]$. This gives a wide germination period, ranging from late summer into early winter, when the competitive ability of winter annual crops is low. Only a small fraction of A. myosuroides plants emerge in spring [31]. The efficacy of pre- and early post-sowing direct weed control measures is mainly driven by their timing relative to the germination and emergence pattern of the weed seeds in the soil seed bank. This pattern is driven by seed dormancy status and is hence a result of the environmental conditions during seed set and seed ripening [30], as well as the environmental conditions during autumn and early winter. This finding emphasizes that the management of the soil seed bank needs to become the centre of attention for improving the overall weed control efficacy.

The results also suggest that stale seedbed preparation alone, enabled by delaying winter wheat sowing by three weeks on average, can reduce the A. myosuroides infestation level by $25 \%$ on average. This effect can be attributed to stale seedbed preparation stimulating weed seed germination and emergence before crop sowing. Weed emergence before crop sowing is beneficial, since numerous non-selective mechanical and chemical tools are available for weed control at that stage, whereas within-crop control is strongly limited to selective measures. Furthermore, the remaining A. myosuroides plants probably produce less biomass due to the reduced growing period.

The effect of increased crop density on weed density has been demonstrated for numerous monoand dicotyledonous weeds [32-34]. Weiner and Thomas (1986) [35] suggested that weed suppression through increased crop density is based on the crop having an advantage in terms of greater mass, which in turn grants it better access to limited resources. In the present study, the effect of increased winter wheat density in reducing weed density was not clearly apparent. The chosen winter wheat seed rates of 300 and 400 seeds $\mathrm{m}^{-2}$ are still within the current farmers practice in Sweden, which is of course limiting the validity of the presented results. Considering the results of other comparable studies, we suggest to test a wider range of seed rates in similar experimental approaches. However, in practice high seed rates should be promoted due to their potential for securing the competitiveness of the crop stand in the long-term perspective.

A synergistic effect was found for delayed sowing with stale seedbed preparation and herbicide treatment with prosulfocarb and/or iodosulfuron + mesosufuron. The bioavailability of prosulfocarb is 
a complex function of soil characteristics and other environmental conditions during and after herbicide application [36]. There are two possible explanations for the observed synergistic effect of stale seedbed preparation and prosulfocarb treatment that should be studied in further experiments: (i) With stale seedbed preparation, crop residues are better incorporated into the soil and a finer seedbed is achieved. This could improve the bioavailability of prosulfocarb through avoided adsorption of prosulfocarb to crop residues [37] and more uniform distribution of the herbicide on the soil surface. (ii) With delayed sowing, soil and air temperature during and after herbicide application are lower. This could result in reduced growth rate of $A$. myosuroides and hence better uptake of the herbicides through the mesocotyl. Of course, the observed synergistic effect could be a combination of both these explanations.

The observed synergistic effect between stale seedbed preparation and iodosulfuron + mesosulfuron treatment in spring could be explained by the observed weed density reduction (less overlapping) and by reduced plant size and biomass at the time of herbicide application caused by the reduced growing period. The timing of herbicide treatment in spring was the same in all treatment combination containing spring herbicide treatment and irrespective of the timing of crop sowing.

Stale seedbed preparation also reduced the range of variability in the efficacy of all treatment combinations. Therefore, stale seedbed preparation appears to be a valuable tool for securing the efficacy of direct weed control measures in general. The herbicide strategies tested in this study are representative of current farm practice, and therefore our results underline the urgent need for widespread implementation of IWM. Herbicides clearly cannot be relied on as an exclusive tool for A. myosuroides management. With early winter wheat sowing, the effect of herbicides on A. myosuroides density was low and highly variable and this can be expected to become a greater problem as herbicide resistance spreads further amongst $A$. myosuroides populations. We found that, when used alone, the preventive and cultural control measures tested had only a marginal reducing effect on weed density. However, in combination with direct weed control methods, they gave a significant reduction in the efficacy variability and hence have the potential for reducing the risk of resistance development. Other preventive and cultural control measures, such as a suitable crop rotation, may further improve $A$. myosuroides suppression in the absence of herbicides when combined with the preventive and cultural control measures tested in this study.

The analysis of winter wheat yield is representing the effect of sowing strategy and seed rate averaged over the tested herbicide strategies. In this respect, the conclusions that can be drawn from the presented yield data are limited. However, the same patterns observed in weed control efficacy were visible in crop yield. A crop yield increase was found due to stale seedbed preparation, which was most likely caused by the observed improved herbicide efficacy and reduced herbicide variability. Increased winter wheat seed rates combined with stale seedbed preparation could not further improve weed control efficacy and hence not further improve crop yield. This is supporting our finding that the tested high seed rate of 400 seeds $\mathrm{m}^{-2}$ was too low for showing a weed suppressive effect.

Farmers are often relatively reluctant to delay sowing due to the risk of missing the sowing window and to negative effects on wheat yield. No yield decrease from delayed sowing was observed in this study, possibly because the delay was only three weeks on average, rather than the typical practice of delaying late sowing until late October. The use of vigorous and fast-developing crop cultivars would further minimize the risk of negative yield effects when sowing is delayed [20].

\section{Conclusions}

Over a series of six field experiments, we could show that the use of preventive, cultural, and direct weed control methods helps to improve the overall weed control efficacy as well as to reduce efficacy variability. The observed low efficacy of chemical weed control without applying additional preventive and cultural methods has shown that IWM is an imperative. More studies investigating the interaction of IWM tolls have to be conducted in order to utilize the full potential of IWM in different crops. 
Author Contributions: A.M. was responsible for conceptualization, writing and original draft preparation as well as for data analysis and visualization. A.T.S.N. was responsible for funding acquisition, project administration, experimental methodology, investigations, writing and reviewing.

Funding: The main author was supported by the Swedish University of Agricultural Sciences (SLU) via the Platform Plant Protection. The field experiments were funded by the Swedish Board of Agriculture (Jordbruksverket).

Acknowledgments: The authors would like to thank the anonymous reviewers for their valuable comments, Lars Andersson for his advice and comments as well as Mary McAfee for English proofreading.

Conflicts of Interest: The authors declare no conflict of interest.

\section{References}

1. Oerke, E.-C. Crop losses to pests. J. Agric. Sci. 2006, 144, 31. [CrossRef]

2. Lehnhoff, E.; Miller, Z.; Hatfield, P.; Johnson, S.; Scott, T.; Miller, P.; Menalled, F. Organic Agriculture and the Quest for the Holy Grail in Water-Limited Ecosystems: Managing Weeds and Reducing Tillage Intensity. Agriculture 2017, 7, 33. [CrossRef]

3. Haddaway, N.R.; Hedlund, K.; Jackson, L.E.; Kätterer, T.; Lugato, E.; Thomsen, I.K.; Jørgensen, H.B.; Isberg, P.E. How Does Tillage Intensity Affect Soil Organic Carbon? A Systematic Review; BioMed Central: London, UK, 2017; Volume 6, ISBN 1375001701089.

4. Triplett, G.B.; Dick, W.A. No-tillage crop production: A revolution in agriculture! Agron. J. 2008, 100, $153-165$. [CrossRef]

5. Délye, C.; Jasieniuk, M.; Le Corre, V. Deciphering the evolution of herbicide resistance in weeds. Trends Genet. 2013, 29, 649-658. [CrossRef]

6. Kortekamp, A. (Ed.) Herbicides and Environment; Intech Open: London, UK, 2011.

7. Barth, J.A.C.; Steidle, D.; Kuntz, D.; Gocht, T.; Mouvet, C.; von Tümpling, W.; Lobe, I.; Langenhoff, A.; Albrechtsen, H.J.; Janniche, G.S.; et al. Deposition, persistence and turnover of pollutants: First results from the EU project AquaTerra for selected river basins and aquifers. Sci. Total Environ. 2007, 376, 40-50. [CrossRef] [PubMed]

8. Damalas, C.; Koutroubas, S. Farmers' Exposure to Pesticides: Toxicity Types and Ways of Prevention. Toxics 2016, 4, 1. [CrossRef]

9. Gaba, S.; Gabriel, E.; Chadoeuf, J.; Bonneu, F.; Bretagnolle, V. Herbicides do not ensure for higher wheat yield, but eliminate rare plant species. Sci. Rep. 2016, 6, 30112. [CrossRef]

10. Koch, W. Environmental factors affecting the germination of some annual grasses. In Proceedings of the 9 th British Weed Control Conference, Brighton, UK, 18-21 November 1968; pp. 14-19.

11. Naylor, R.E.L. The Prediction of Blackgrass Infestations. Weed Res. 1970, 10, 296-299. [CrossRef]

12. Colbach, N.; Dürr, C.; Chauvel, B.; Richard, G. Effect of environmental conditions on Alopecurus myosuroides germination. II. Effect of moisture conditions and storage length. Weed Res. 2002, 42, 222-230. [CrossRef]

13. Barallis, G. Ecology of blackgrass. In Proceedings of the 9th British Weed Control Conference, Brighton, UK, 18-21 November 1968; pp. 6-8.

14. Heap, I. The International Survey of Herbicide Resistant Weeds. Available online: www.weedscience.com (accessed on 26 April 2017).

15. Moss, S.R.; Clarke, J.H. Guidelines for the prevention and control of herbicide-resistant black-grass (Alopecurus myosuroides Huds.). Crop Prot. 1994, 13, 230-234. [CrossRef]

16. Swanton, C.J.; Weise, S.F. Integrated Weed Management: The Rationale and Approach. Weed Technol. 1991, 5, 657-663. [CrossRef]

17. Bàrberi, P. Ecological weed management in Sub-Saharan Africa: Prospects and implications on other agroecosystem services. Adv. Agron. 2019, 156, 219-264.

18. Vasileiadis, V.P.; Dachbrodt-Saaydeh, S.; Kudsk, P.; Colnenne-David, C.; Leprince, F.; Holb, I.J.; Kierzek, R.; Furlan, L.; Loddo, D.; Melander, B.; et al. Sustainability of European winter wheat- and maize-based cropping systems: Economic, environmental and social ex-post assessment of conventional and IPM-based systems. Crop Prot. 2016, 97, 60-69. [CrossRef]

19. Andrew, I.K.S.; Storkey, J.; Sparkes, D.L. A review of the potential for competitive cereal cultivars as a tool in integrated weed management. Weed Res. 2015, 55, 239-248. [CrossRef] [PubMed] 
20. Lutman, P.J.W.; Moss, S.R.; Cook, S.; Welham, S.J. A review of the effects of crop agronomy on the management of Alopecurus myosuroides. Weed Res. 2013, 53, 299-313. [CrossRef]

21. Andrew, I.K.S.; Storkey, J. Using simulation models to investigate the cumulative effects of sowing rate, sowing date and cultivar choice on weed competition. Crop Prot. 2017, 95, 109-115. [CrossRef] [PubMed]

22. Nakagawa, S.; Schielzeth, H. A general and simple method for obtaining R2 from generalized linear mixed-effects models. Methods Ecol. Evol. 2013, 4, 133-142. [CrossRef]

23. Nakagawa, S.; Schielzeth, H. Coefficient of determination R2 and intra-class correlation coefficient from generalized linear mixed-effects models revisited and expanded. J. R. Soc. Interface 2017, 14, 20170213. [CrossRef]

24. Akaike, H. Information theory and an extension of the maximum likelihood principle. In Proceedings of the 2nd International Symposium on Information Theory, Tsahkadsor, Armenia, 2-8 September 1971; Hirotugu Akaike: Budapest, Hungary, 1973; pp. 267-281.

25. Johnson, J.B.; Omland, K.S. Model selection in ecology and evolution. Trends Ecol. Evol. 2004, 19, 101-108. [CrossRef]

26. R Development Core Team R: A Language and Environment for Statistical Computing. Available online: http://www.r-project.org (accessed on 2 January 2019).

27. Colby, S.R. Calculating Synergistic and Antagonistic Responses of Herbicide Combinations. Weeds 1967, 15, 20-22. [CrossRef]

28. Brown, B.; Gallandt, E.R. Evidence of synergy with 'stacked' intrarow cultivation tools. Weed Res. 2018, 58, 284-291. [CrossRef]

29. Colbach, N.; Chauvel, B.; Dürr, C.; Richard, G. Effect of environmental conditions on Alopecurus myosuroides germination. I. Effect of temperature and light. Weed Res. 2002, 42, 210-221. [CrossRef]

30. Menegat, A.; Milberg, P.; Nilsson, A.T.S.; Andersson, L.; Vico, G. Soil water potential and temperature sum during reproductive growth control seed dormancy in Alopecurus myosuroides Huds. Ecol. Evol. 2018, 8, 7186-7194. [CrossRef] [PubMed]

31. Wallgren, B.; Avholm, K. Dormancy and germination of Apera spica-venti L. and Alopecurus myosuroides Huds seeds. Swed. J. Agric. Res. 1978, 8, 11-15.

32. Menegat, A.; Jäck, O.; Zhang, J.; Kleinknecht, K.; Müller, B.U.; Piepho, H.-P.; Ni, H.; Gerhards, R. Japanese Bindweed (Calystegia hederacea) Abundance and Response to Winter Wheat Seeding Rate and Nitrogen Fertilization in the North China Plain. Weed Technol. 2013, 27, 768-777. [CrossRef]

33. Olsen, J.; Kristense, L.; Weiner, J. Effects of density and spatial pattern of winter wheat on suppression of different weed species. Weed Sci. 2005, 53, 690-694. [CrossRef]

34. Wicks, G.A.; Nordquist, P.T.; Baenziger, P.S.; Klein, R.N.; Hammons, R.H.; Watkins, J.E. Winter wheat cultivar characteristics affect annual weed suppression. Weed Technol. 2004, 18, 988-998. [CrossRef]

35. Weiner, J.; Thomas, S.C. Size Variability and Competition in Plant Monocultures. OIKOS 1986, 47, $211-222$. [CrossRef]

36. Bailly, G.C. Effectiveness of Prosulfocarb-Based Treatments for the Control of Sensitive and Herbicide Resistant Lolium spp. Populations. Ph.D. Thesis, Imperial College London, London, UK, 2011.

37. Khalil, Y.; Flower, K.; Siddique, K.H.M.; Ward, P. Effect of crop residues on interception and activity of prosulfocarb, pyroxasulfone, and trifluralin. PLOS ONE 2018, 13, 1-19. [CrossRef]

(C) 2019 by the authors. Licensee MDPI, Basel, Switzerland. This article is an open access article distributed under the terms and conditions of the Creative Commons Attribution (CC BY) license (http://creativecommons.org/licenses/by/4.0/). 